\title{
PCR testing for diagnosis of Ichthyophonus hoferi: Reply to LaPatra \& Kocan (2013)
}

\author{
Toshihide Hamazaki ${ }^{1, *}$, Eryn Kahler ${ }^{1}$, Bonnie M. Borba ${ }^{2}$, Tamara Burton ${ }^{1}$ \\ ${ }^{1}$ Alaska Department of Fish and Game, Division of Commercial Fisheries, 333 Raspberry Road, Anchorage, Alaska 99518, USA \\ ${ }^{2}$ Alaska Department of Fish and Game, Division of Commercial Fisheries, 1300 College Road, Fairbanks, Alaska 99701, USA
}

\begin{abstract}
LaPatra \& Kocan (2013) critiqued our paper Hamazaki et al. (2013; Dis Aquat Org 105:21-25) for data not supporting the conclusions of 'PCR testing is as accurate as culture...', but they neither pointed out what part of our data did not support our conclusion, nor did they provide any contrary scientific evidence supporting their argument that PCR testing is less accurate than culture. In the absence of any contradictory data, we stand by our data and our conclusion: PCR test is as suitable as culture as a diagnostic and field surveillance tool.
\end{abstract}

KEY WORDS: Ichthyophonus hoferi $\cdot$ Explant culture $\cdot$ Polymerase chain reaction $\cdot$ Diagnosis · Confirmation

While LaPatra \& Kocan (2013) critiqued that our dataset did not support our conclusion that 'PCR testing can be as accurate as culture for diagnosis of Ichthyophonus hoferi ...' (Hamazaki et al. 2013), they did not dispute the validity of our data: greater then $90 \%$ sensitivity, greater than $97 \%$ specificity, and greater than $96 \%$ agreement between culture and conventional polymerase chain reaction $(\mathrm{PCR}$, or more precisely cPCR) for diagnosing Ichthyophonus infection. Nor did they present any counter scientific evidence that cPCR testing is less accurate than culture testing. Instead, they criticised our paper for overstating the usefulness of the CPCR test as a suitable diagnostic and field surveillance tool; however, statistically identical estimates of Ichthyophonus infection prevalence between culture and cPCR tests (Kahler et al. 2011, Hamazaki et al. 2013) prove that the cPCR test is as suitable as culture as a field surveillance tool. We respond here to the specific criticisms: (1) possibility of cPCR and impossibility of culture for 'false positives', (2) evaluation of cPCR tests not strictly adhering to the World Organization for Animal Health (OIE) guideline protocol (OIE 2013), (3) our dismissal of Whipps et al. (2006) on low sensitivity of cPCR.
Every diagnostic technique can generate both 'false negatives' and 'false positives.' For a technique using assays, 'false positives' can come from a fish that was exposed to but not necessarily infected with a pathogen, or from a fish that had recovered from an infection. On the other hand, for direct visual techniques 'false positives' can come from misidentification of a pathogen, for which LaPatra \& Kocan (2013) acknowledge use of cPCR as suitable for confirming identity of a pathogen, including identification of Ichthyophonus at the species level (Criscione et al. 2002). Acknowledging that every technique is prone to errors of both 'false positives' and 'false negatives', the major question is whether (or which) errors are problematic for a population of interest and surveillance objective. It is likely that a diagnostic technique suitable for one population and objective may not be suitable for other populations and other objectives.

Thus, under the guidelines of the World Organization for Animal Health (OIE 2013), evaluation of a diagnostic technique should ideally be conducted using known positive/negative reference samples from the target population (e.g. Yukon River Chinook 
salmon). Using laboratory samples (e.g. hatchery raised Chinook salmon artificially fed with Ichthyophonus infected prey) is not ideal because those samples may not represent the true infection status of the target population (OIE 2013, Chapter 1.1.2). For the Yukon River Chinook salmon, sources and routes of Ichthyophonus have not been identified. Acknowledging the difficulties of obtaining true ideal reference samples, the OIE guideline accepts using samples identified by another test of sufficiently high accuracy (OIE 2013, Chapter 1.1.2). Since culture has been used as a standard for diagnosis of Ichthyophonus (Kocan et al. 2011), using culture as reference samples (Hamazaki et al. 2013) is entirely in accord with the guideline not only of the OIE but also the UNICEF/UNDP/World Bank/WHO Special Programme for Research and Training in Tropical Diseases (TDR) Diagnostic Evaluation Expert Panel (Banoo et al. 2008).

We dismissed Whipps et al. (2006)'s results for low sensitivity of $\mathrm{cPCR}$ because of small sample size ( $\mathrm{n}=$ 6 to 7 ) and a misleading definition of infection severity ('light' vs. 'heavy') that does not necessarily correspond to intensity of infection or pathogen load (Hamazaki et al. 2013). Results from small samples have no statistical confidence and validity. It is our opinion that their flawed data should not have been reported, let alone be generalized. For this reason we included datasets of Whipps et al. (2006) in our study (Table 2 in Hamazaki et al. 2013), so that readers can reproduce and evaluate the validity of our conclusions. Moreover, it is unclear why LaPatra \& Kocan (2013) pay special attention to this Whipps et al. (2006)'s flawed and questionable finding, while they ignore Whipps et al. (2006)'s major findings of greater than $90 \%$ of sensitivity and specificity (n > 300) for diagnosing Ichthyophonus infection (Table 2 in Whipps et al. 2006).

Finally, LaPatra \& Kocan (2013)'s critique of our overstatement of the usefulness of the CPCR test as a field surveillance tool is irrelevant because usefulness of a diagnostic test is determined by research objectives. For example, Zuray, Kocan and Hershberger (2012) employed a diagnostic criterion of 'presence of visible lesions on heart tissue' for surveillance of Ichthyophonus disease prevalence of the Yukon River Chinook salmon in the upriver. Obviously, this criterion is much less accurate than the culture or the PCR tests and subject to errors of both 'false positives' (e.g. visible lesions caused by other pathogens) and 'false negatives' (e.g. diseased fish not developing lesions). However, it can be reasonable for discerning a longterm trend of Ichthyophonus disease prevalence, given that the observed trend was similar to that at the mouth of the Yukon River using culture/PCR tests (JTC 2013). As this example illustrates, while employing the most accurate diagnostic test is preferable, the most important criteria is whether a diagnostic test can sufficiently meet research objectives.

In conclusion, in the absence of contrary scientific evidence, we stand by our data and conclusion that the PCR test is as good as culture for diagnosis of Ichthyophonus infection. It is our opinion that researchers should choose the most appropriate diagnostic tool based on the needs of their research objectives and field circumstances.

\section{LITERATURE CITED}

Banoo S, Bell D, Bossuyt P, Herring A and others (2008) Evaluation of diagnostic tests for infectious diseases: general principles. Nat Rev Microbiol 6:S16-S28

Criscione CD, Watral V, Whipps CM, Blouin MS, Jones SRM, Kent ML (2002) Ribosomal DNA sequences indicate isolated population of Ichthyophonus hoferi in geographic sympatry in the north-eastern Pacific Ocean. J Fish Dis 25:575-582

Hamazaki T, Kahler E, Borba BM, Burton T (2013) PCR testing can be as accurate as culture for diagnosis of Ichthyophonus hoferi in Yukon River Chinook salmon Oncorhynchus tshawytscha. Dis Aquat Org 105:21-25

JTC (Joint Technical Committee of the Yukon River US/Canada Panel) (2013) Yukon River salmon 2012 season summary and 2013 season outlook. Regional Information Report 3A13-02, Alaska Department of Fish \& Game, Anchorage, AK

Kahler E, Borba BM, Burton T, Dehn LA, Hamazaki T, Jasper JR (2011) Prevalence of Ichthyophonus in Chinook salmon entering the Yukon River and Tanana stock spawning grounds, 2004-2006. Fishery Data Series No. 11-11, Alaska Department of Fish \& Game, Anchorage, AK

> LaPatra SE, Kocan RM (2013) PCR testing for diagnosis of Ichthyophonus hoferi: Comment on Hamazaki et al. (2013). Dis Aquat Org 106:273-274

> Kocan R, Dolan H, Hershberger P (2011) Diagnostic methodology is critical for accurately determining the prevalence of Ichthyophonus infections in wild fish populations. J Parasitol 97:344-348

OIE (Office International des Epizooties) (2013) Principles and methods of validation of diagnostic assays for infectious diseases. In: OIE Manual of Diagnostic Tests for Aquatic Animals 2013. World Organization for Animal Health. Available at www.oie.int/en/international-standard-setting/aquatic-manual/access-online/ (accessed October 3, 2013)

Whipps CM, Burton T, Watral TVG, St-Hilaire S, Kent ML (2006) Assessing the accuracy of a polymerase chain reaction test for Ichthyophonus hoferi in Yukon River Chinook salmon Oncorhynchus tshawytscha. Dis Aquat Org 68:141-147

Zuray S, Kocan R, Hershberger P (2012) Synchronous cycling of Ichthyophoniasis with Chinook salmon density revealed during the annual Yukon River spawning migration. Trans Am Fish Soc 141:615-623 